\title{
Explosive compaction: design, implementation and effectiveness
}

\author{
W. B. GOHL,${ }^{*}$ M. G. JEFFERIES, $\dagger$ J. A. HOWIE $\$$ and D. DIGGLE
}

\begin{abstract}
Although used for over 70 years, Explosive Compaction (EC) has not attained widespread acceptance despite the attraction of low cost and ease of treating large depths. Lack of familiarity with the method, and an empirical design approach unrelated to theory, appear the primary cause for reticence in adopting EC. To alleviate these concerns, practical design considerations for EC based on detailed experience from nine applications and trials are presented here to illustrate the predictable and repeatable effectiveness of EC. Design is based on cavity expansion theory. EC readily gives volume changes 2-3 times larger than might occur under large earthquake motions, with final average relative densities often greater than $70 \%$. Further, environmental and vibration control issues do not constrain the use of EC provided that appropriate explosives and delayed detonation sequences are used. As pronounced post-blast time effects are evident in penetration testing, evaluation of the effectiveness of EC should be based on a combination of pre- and post-blast penetration testing and volume change measurements.
\end{abstract}

KEYWORDS: compaction; ground improvement; liquefaction; sand.
Bien qu'utilisée depuis plus de 70 ans, la méthode de compactage aux explosifs (CE) n'est pas encore acceptée de manière universelle malgré son faible coût et son efficacité pour les grandes profondeurs. Cette méthode est mal connue et la cause principale de cette réticence à l'adopter semble être son caractère empirique, dissocié de la théorie. Pour apaiser les craintes, et pour prouver son efficacité prévisible et reproductible, nous présentons ici les fondements pratiques de la méthode $\mathrm{CE}$ en nous basant sur une expérience détaillée dérivée de neuf applications et essais. Le principe repose sur la théorie de l'expansion de cavité. La méthode CE produit des changements de volume de 2 à 3 fois plus importants que ceux qui peuvent se produire pendant les forts mouvements sismiques, avec des densités relatives moyennes finales souvent supérieures à $70 \%$. De plus, les questions d'environnement et de contrôle des vibrations ne limitent pas l'utilisation de la méthode $\mathrm{CE}$ du moment qu'on emploie des explosifs appropriés et des séquences de détonation à retardement. Etant donné que des effets de temps prononcés post-explosion sont évidents dans les essais de pénétration, l'évaluation de l'efficacité de la méthode CE devra être basée sur une combinaison d'essais de pré et post explosion et de mesures des changements de volume.

\section{INTRODUCTION}

Explosive compaction (EC) has been used in various projects throughout the world over the last 70 years. EC involves placing a charge at depth in a borehole in loose soil (generally sands to silty sands or sands and gravels), and then detonating the charge. Several charges are fired at one time, with delays between each charge to enhance cyclic loading while minimizing peak acceleration. Often several charges will be stacked in one borehole with gravel stemming between each charge to prevent sympathetic detonation.

EC is attractive, as explosives are an inexpensive source of readily transported energy and allow densification with substantial savings over alternative methods. Only small-scale equipment is needed (e.g. geotechnical drill or wash boring rigs), minimizing mobilization costs and allowing work in confined conditions. Compaction can be carried out at depths beyond the reach of conventional ground treatment equipment.

Most EC has been driven by concerns over liquefaction, and has been on loose soils below the water table (and to depths of nearly $50 \mathrm{~m}$ ). However, compaction also increases ground stiffness and strength, and EC has wide application for general ground improvement.

Like many other geotechnical processes, explosive compaction has been designed largely on experience rather than theory. It is common to carry out a trial before starting full-scale treatment. This empirical design basis appears to be an obstacle to the widespread use of an otherwise inexpensive and effective compaction method: owner's review boards are often reticent in approving proposals, contractors are unsure of risk factors when bidding work, and consulting geotechnical engineers lack famil-

Manuscript received 7 February 2000; revised manuscript accepted 28 June 2000.

Discussion on this paper closes 22 February 2001, for further details see p. ii.

* Pacific Geodynamics Inc., Canada.

$\leftarrow$ Golder Associates \& UMIST, UK.

$\$$ University of British Columbia, Canada.

$\S$ Foundex Explorations Ltd, Canada. iarity with the method. The aim of this paper is to present detailed experience from several applications to counter these concerns, explaining the methodology used. EC can be systematically designed, and can achieve repeatable and consistent results. We also consider environmental, vibration, and other incidental effects to illustrate that these will not usually constrain EC.

\section{TYPICAL GROUND RESPONSE DURING EXPLOSIVE} COMPACTION

Similar ground response was observed at the sites discussed in this paper: compaction does not occur concurrently with explosive detonation. Following detonation of the charges, some immediate ground heave or small settlements occurs around individual blast holes. Nothing is then apparent at ground surface for at least several minutes or, in the case of fine sand, tens of minutes; then the ground starts to settle, and continues to settle for upwards of an hour. Compaction induced by explosives is not over the few seconds of explosive detonation but rather is an induced consolidation over several hours, even with sandy gravels. Explosives generate residual excess pore water pressure that dissipates and results in consolidationrelated compaction.

Where the water table is near the surface, and there is no overlying impermeable layer, sand boils usually develop as the residual excess pore water migrates at depth and forms preferential pathways to the surface. The vertical seepage pipes associated with these sand boils can be $100 \mathrm{~mm}$ or more in diameter (we have seen them as large as $600 \mathrm{~mm}$ ), and large quantities of water escape to the surface through them. Pore water escapes for perhaps as long as $2 \mathrm{~h}$. If the water table is at depth, or if there is an overlying impervious layer, then sand boils develop around the blast holes.

The ground settles concurrently with the escape of pore water. Settlements may continue at a slow rate depending on soil permeability and drainage conditions. Once an area of ground has been shot and pore pressures have largely dissipated, blasting from adjacent areas causes additional settlement de- 
pending on soil density and stiffness. The first detonation sequence of blast holes (first pass) destroys any bonds existing between sand grains due to ageing and other geologic processes, and causes the majority of settlement within the soil mass. Subsequent passes cause additional settlement by cyclic straining.

Penetration resistance of the compacted sands shows pronounced time dependence. Some case histories show no increase or even a decrease in penetration resistance immediately after blasting, while other case histories show only a modest increase in resistance. However, the penetration resistance two weeks after blasting is often double the pre-compaction value. Delayed strength gain must be allowed for in developing an explosive compaction project if penetration resistance is the basis for the work. An example of delayed strength gain and achievable penetration resistance is shown in Fig. 1.

\section{THEORY}

Historically, charge weights and spacing have been selected based on empirically derived correlations between explosive charge density and induced post-blast settlement. Vibrations (peak particle velocities) are controlled on the basis of empirically derived relationships between observed ground velocities, distance from the blast and explosive charge mass per delay. Blast effectiveness and the magnitude of vibrations vary with the soil conditions, type of explosive, charge length, blast hole layout and the sequence of detonation. A more theoretical basis for design is desirable.

\section{Dimensional analysis}

Detonation of an explosive produces two forms of energy release; the shock wave from the detonation front, and the work done by the high-pressure gas formed in the explosion as it expands. About one third of the charge energy is available for work in expanding the cavity containing the charge, and it is this component that is of interest for compacting the soil. The shock wave is predominantly a compression wave, although

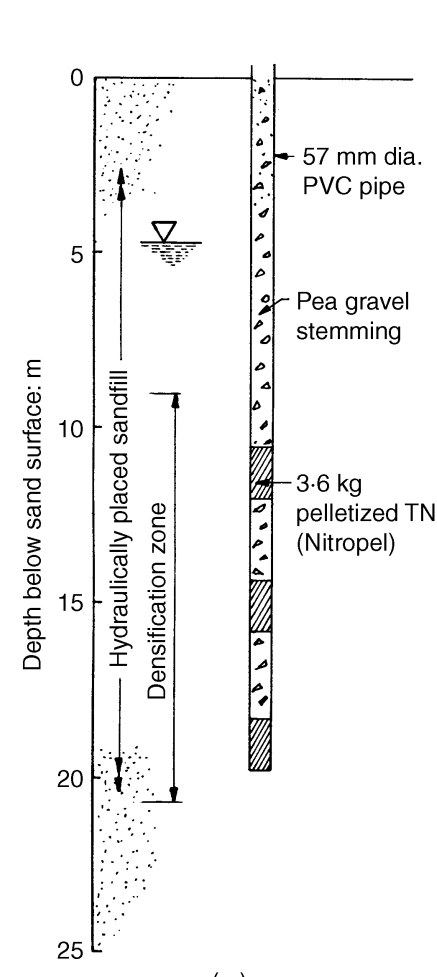

(a)

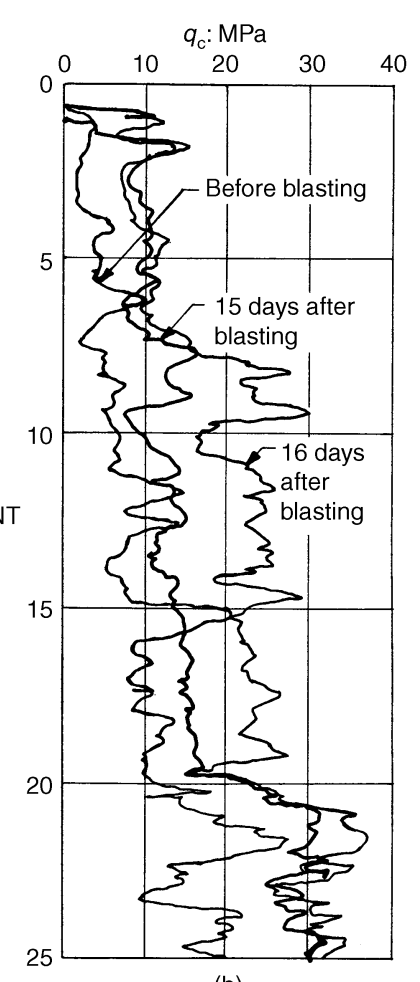

(b)
Fig. 1. Example of (a) explosive compaction loading (after Stewart \& Hodge, 1988) and (b) achieved change in CPT resistance (after Rogers et al., 1990) shear waves are formed at the corners of cylindrical charges. However, the cavity expansion is pure shear in the elastic phase, and largely shear in the elastic-plastic stage.

Most work on explosive compaction has relied on similitude in examining trends in the experience record, adopting Hopkinson's number $(H N)$ to estimate empirically the radius of influence around a blast hole. $H N$ is often taken to be

$$
H N=W^{0.33} / r
$$

where $W$ is the charge mass delay $(\mathrm{kg})$, and $r$ is the distance from the charge to the point of interest. But equation $(1)$ is not dimensionless. The characteristic size of the explosive charge is

$$
z=(W / \rho)^{0.33}
$$

where $\rho$ is the mass density of the explosive, and $z$ is the face length of an equivalent cubical source. Although adopting $W$ without regard to explosive type might seem too simple given the differing bulk strength of various explosives, it is difficult to discern an effect of explosive type in the experience record because of the variation in the proportion of energy radiated in the blast wave from one explosive and charge arrangement to another. Thus $W$ is used at face value without regard to explosive heat content or detonation pressure.

A consistent form of $H N$ is

$$
H N=z / r=(W / \rho)^{0.33} / r
$$

Using dimensional analysis (Chadwick et al., 1964; Higgins et al., 1978), the effectiveness of an explosion, $E$, can be expressed as

$$
E=f\left(H N, t^{\prime}, h / z, g h / V_{\mathrm{s}}^{2}, \varphi^{\prime}, \lambda, \ldots\right)
$$

where $t^{\prime}$ is dimensionless time, $h / z$ is the burial depth ratio, and the other parameters relate to the elastic/plastic properties of the soil. Thus the blast effectiveness is a function of charge density, time, the strength and stiffness of the soil, and two terms related to the depth of the charge. Because stiffness is strongly dependent on the square root of the effective stress, a first approximation of charge effectiveness in a given soil type is

$$
E=k(W / \rho)^{0.5} h^{-0.5} R^{-1}
$$

where $E$ is the fraction of maximum achievable vertical strain, $R$ is the radius of a circle of area equal to the rectangular/ triangular region compacted by a blast hole, and $k$ is a sitespecific coefficient related to the soil properties and damping. The time term has been dropped, as interest is in the induced plastic strains, not the ground motion during the blast. Equation (5) implies that for maximum effectiveness the charge weights must increase with depth. Design using a constant $H N$ or constant loading factor will give less than optimum compaction.

\section{Cavity expansion}

Although equation (5) provides a first estimate for design (given knowledge of $k$, some values of which are provided later), improved understanding can be gained from treating detonation of an explosive charge as the rapid expansion of a cavity. Cavity expansion is primarily a shearing phenomenon, with the expansion and then collapse of a cavity inducing a cycle of shear strain within the soil. The magnitude of the strain diminishes with distance from the blast, and the radius of influence of a particular charge detonation depends on the size and geometry of the charge and the rate of energy release relative to the properties of the soil.

$\mathrm{Wu}(1995,1996)$ developed a non-linear, spherically symmetric finite element program that assumes that a charge detonation may be idealized by assuming a blast pressure-time input applied normal to the surface of a spherical cavity. Soil is represented by a hyperbolic constitutive model, using the Masing criterion to represent hysteretic effects. The high strain rates with blast-induced cavity expansion require a viscous component of strength in the model for realistic predictions: a simple 
linear (Newtonian) dependence on shear strain rate is used. The program outputs dynamic shearing strains, ground accelerations and velocities, plastic volume change potential and residual pore water pressures for both single and multiple charge detonations. The approach used in the $\mathrm{Wu}$ model is by no means a rigorous representation of soil physics, but captures an engineering approximation given appropriate calibration.

Soil behaviour observed in laboratory testing has shown that a minimum threshold shear strain is necessary to initiate pore pressure generation (e.g. Dobry et al., 1982), and that multiple cycles of shear strain are more effective than single cycles. Superposition of spherically symmetric models, allowing for the relevant distances, simulates 3-D arrays of blast holes with reasonable results obtained provided that the model is first calibrated by analysis of test blasts at the site in question.

The effect of the detonation of multiple charges in finegrained sand is shown in Fig. 2. The residual pore pressure increases after each detonation and in the expected way. Also shown is a multi-blast simulation using the $\mathrm{Wu}$ model, showing that pore water pressures are reasonably modelled.

\section{Implications of the theory}

Summarizing, theory indicates that:

(a) The initial induced pore pressure during blasting reflects the increase in total stress due to the detonation shock wave.

(b) The accumulated shear strains govern the amount of settlement achieved, and are reflected in the residual excess pore water pressure. Multiple cycles of a given shear strain level will be more effective than single cycles.

(c) The zone of influence of a given charge detonation increases as the size of the cavity increases, but the radius of the zone of disturbance caused by a given charge will depend on the mean confining stress and the strength and stiffness of the soil surrounding it.

(d) To create the same radius of zone of disturbance, it will be necessary to increase the charge weight as the depth increases, as stress, strength and stiffness generally increase with depth. Dimensional analysis suggests that a charge mass should increase proportionally to the square root of the depth.

In practice this theoretical guidance requires explosive charges distributed and timed to maximize the magnitude and number of cycles of shear strain of the soil in the zone being densified. But there is little point in detonating charges in a zone that has liquefied because of adjacent charges; pore pressures should be allowed to dissipate first. Wave theory can be used (e.g. the Wu model) to estimate the peak shear strains and corresponding

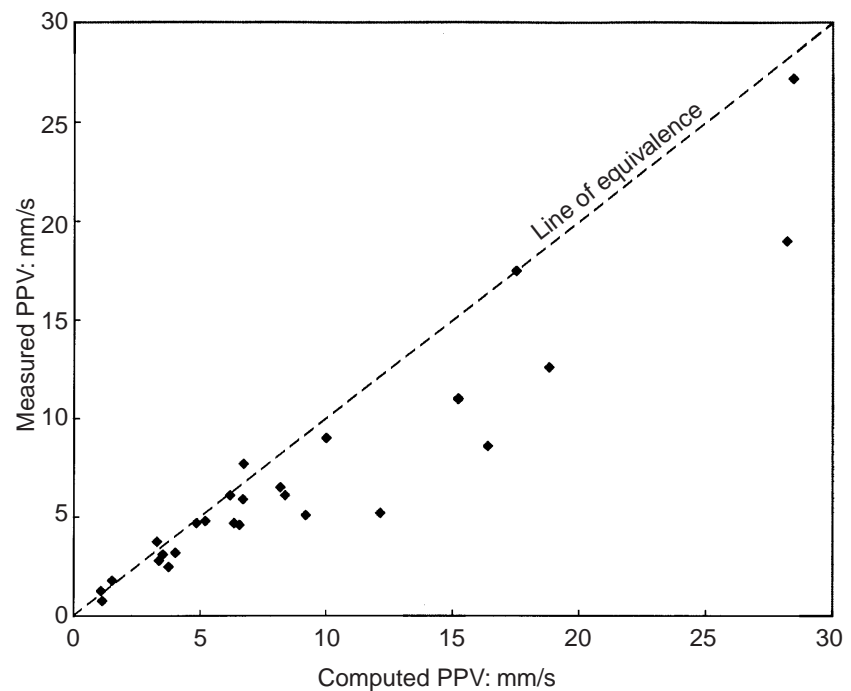

Fig. 3. Blast wave simulation: measured PPV plotted against computed PPV

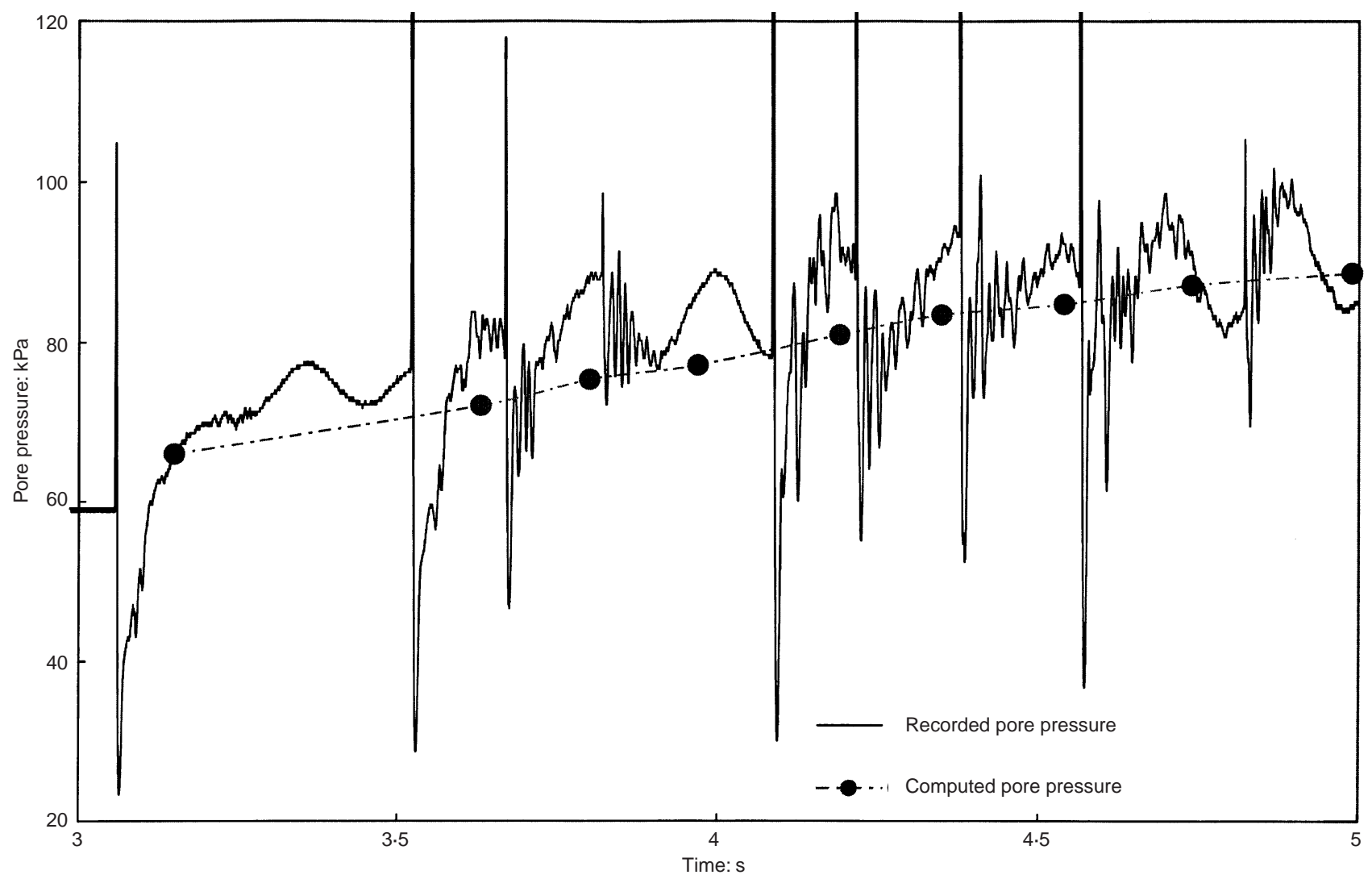

Fig. 2. Excess residual pore pressure induced by explosive compaction 
Table 1. Summary of case histories

\begin{tabular}{|c|c|c|c|c|c|c|c|c|}
\hline Project and year & $\begin{array}{l}\text { Volume: } \mathrm{m}^{3} \\
\text { Max. depth: } \mathrm{m}\end{array}$ & Soil type & $\begin{array}{l}\text { Site factor } k \\
\text { (eqn }(5))\end{array}$ & $\begin{array}{l}\text { Initial avg. } \\
\quad D_{\mathrm{r}}: \%\end{array}$ & $\begin{array}{l}\text { Charge density: } \\
\mathrm{g} / \mathrm{m}^{3}\end{array}$ & $\begin{array}{l}\text { Volume change: } \\
\%\end{array}$ & $\begin{array}{l}\text { Final avg. } \\
D_{\mathrm{r}}: \%\end{array}$ & Key considerations \\
\hline $\begin{array}{l}\text { Molikpaq I, } \\
\text { Amauligak } \\
\text { (1986) }\end{array}$ & $\begin{array}{r}67000 \\
21\end{array}$ & $\begin{array}{l}\text { Clean dredged } \\
\text { medium fine sand }\end{array}$ & 117 & 45 & Nitropel 36 & $6 \cdot 4$ & 75 & $\begin{array}{l}\text { Limited headroom for drilling equipment, rapid EC execution, on- } \\
\text { board safety, blast pressures on hull of structure, meeting CPT }\end{array}$ \\
\hline $\begin{array}{l}\text { Molikpaq II, } \\
\text { Sakhalin (1998) }\end{array}$ & $\begin{array}{r}169000 \\
41\end{array}$ & $\begin{array}{l}\text { Clean dredged } \\
\text { medium coarse } \\
\text { sand }\end{array}$ & 143 & 35 & Super Blastex 52 & $8 \cdot 0$ & 75 & specification \\
\hline Trans-X (1993) & $\begin{array}{r}65000 \\
15\end{array}$ & $\begin{array}{l}\text { Medium fine } \\
\text { alluvial sand with } \\
\text { silt layers }\end{array}$ & 100 & 50 & Iremite TX 37 & $3 \cdot 7$ & 70 & $\begin{array}{l}\text { Limiting PPVs in urban environment, adequate densification for } \\
\text { seismic liquefaction control }\end{array}$ \\
\hline $\begin{array}{l}\text { Quebec HQ SM-3 } \\
\text { Dam (1995) }\end{array}$ & $\begin{array}{r}200000 \\
20\end{array}$ & $\begin{array}{l}\text { Clean alluvial } \\
\text { fine to coarse } \\
\text { sand }\end{array}$ & 99 & 45 & Emulsion 38 & $6 \cdot 2$ & 75 & $\begin{array}{l}\text { Limiting hydrodynamic water pressures on ice sheet, meeting CPT } \\
\text { specification }\end{array}$ \\
\hline $\begin{array}{l}\text { Coldwater Creek } \\
\text { (1992) }\end{array}$ & $\begin{array}{r}90000 \\
40\end{array}$ & $\begin{array}{l}\text { Silty sand, } \\
\text { gravel, cobbles }\end{array}$ & 81 & 50 & Nitropel 42 & $3 \cdot 6$ & 65 & $\begin{array}{l}\text { Minimizing slope instability adequate densification for seismic } \\
\text { liquefaction control }\end{array}$ \\
\hline $\begin{array}{l}\text { Kitimat Hospital } \\
\text { (1998) }\end{array}$ & $\begin{array}{r}27000 \\
12\end{array}$ & $\begin{array}{l}\text { Layered silty } \\
\text { sand and sand }\end{array}$ & 101 & $\begin{array}{l}>45 \\
\text { (Variable) }\end{array}$ & Super Blastex 48 & $\begin{array}{l}3.5 \text { overall } \\
4.7 \text { in sands }\end{array}$ & $\begin{array}{c}>70 \text { in cleaner } \\
\text { sand layers }\end{array}$ & $\begin{array}{l}\text { Vibration control, reducing potential earthquake settlements, } \\
\text { maximizing CPT resistances }\end{array}$ \\
\hline $\begin{array}{l}\text { Sato Kogyo* } \\
\text { (1997) }\end{array}$ & $\begin{array}{r}1125 \\
12\end{array}$ & $\begin{array}{l}\text { Alluvial silty } \\
\text { sand and n.p. silt }\end{array}$ & - & $\sim 45$ & Emulite 53 & $7 \cdot 0$ & $2-3 \times$ increase in & $\begin{array}{l}\text { Vibration control, maximizing post-blast settlements and penetration } \\
\text { resistances }\end{array}$ \\
\hline Kelowna* (1991) & $\begin{array}{r}8000 \\
10\end{array}$ & Sand to silty sand & 104 & 25 & Extragel (75) 9 & $5 \cdot 5$ & 50 & Ground improvement against liquefaction \\
\hline $\begin{array}{l}\text { Elliot Lake* } \\
(1980)\end{array}$ & $\begin{array}{r}1000 \\
6\end{array}$ & Silt tailings & - & $\begin{array}{l}\sim 35 \\
\text { equivalent }\end{array}$ & Kinestick 5 & $4 \cdot 2$ & $\begin{array}{c}q_{\mathrm{c}} \text { increased by } \\
2-3 \text { times }\end{array}$ & Behaviour of silt under earthquake loading \\
\hline
\end{tabular}

*Denotes field trial. 
residual pore water pressures, with the site-specific factors determined by analysis of a small trial blast.

\section{PRACTICAL CONSIDERATIONS}

\section{Vibration control}

Induced vibrations on nearby structures need to be controlled where blast densification is carried out in developed areas. Blasting within $30-40 \mathrm{~m}$ of existing structures requires a reduction in the charge weights per deck (involving a reduction in blast hole spacings), and in the number of holes detonated at any one time. Also, when blasting is carried out on or adjacent to slopes, blast patterns are adjusted to restrict the zone of residual pore water pressure build-up and minimize the risk of slope instability.

For the above reasons, the number of charges detonated sequentially is often restricted to minimize the duration of shaking. Longer-duration shaking causes more damage to structures and increases residual pore water pressure build-up. Individual charge delays are also selected so that destructive interference in the frequency range of interest occurs between ground waves from the sequence of blasts. Design of the appropriate charge delays between adjacent decks in each borehole and between adjacent boreholes is carried out using the following process:

(a) Ground vibration patterns (peak particle velocities and frequency content) are determined at a particular location of concern remote from the blast point due to a single charge. This is best done using field measurements, but can also be carried out theoretically.

(b) The frequency range of potentially damaging vibrations is selected based on structural vibration theory or other considerations.

(c) The effects of sequential charge detonation from a decked array of boreholes are assessed by a simple linear combination of the single charge wave trains in which time delays between decks and between adjacent boreholes are varied. Optimum blast delays are then determined to minimize the peak particle velocity or, alternatively, the vibrational energy content in the frequency range of interest.

Based on vibration measurements recorded during detonation of a single charge at various distances from a blast source at an alluvial site in Japan, the linear wave superposition model described above was applied to compute the likely peak particle velocities (PPV) at the ground surface for a particular direction resulting from multiple detonations. The computed and measured peak velocities are plotted against each other in Fig. 3 and indicate that the use of linear combination of wave motions (incorporating appropriate time-shifts in the waveforms based on the prescribed detonation sequence and waveform scaling depending on charge weight-distance relationships determined for the site) generally leads to a conservative over-prediction of PPV. This is particularly true for small source-site distances, where non-linear effects caused by soil liquefaction around a blast point would be expected to reduce near-field motions.

\section{Blast hole layout and detonation sequencing}

Blast patterns generally use a staggered rectangular grid of boreholes at spacings of 4-9 $\mathrm{m}$. Staggering is used to provide a pattern of two (or more) passes within a uniform grid. Boreholes are drilled over the full depth of soil deposit to be densified, and $75-100 \mathrm{~mm}$ diameter plastic casing installed (this casing size is convenient with the drills normally used). The casing is then loaded with explosive at one or more levels in the borehole (decks). A series of boreholes, each containing one or more decks, is then sequentially detonated. The number of blast holes detonated in any shot depends on vibration control considerations and on concerns about the effect of liquefaction and settlement on adjacent slopes and structures. Subsequent

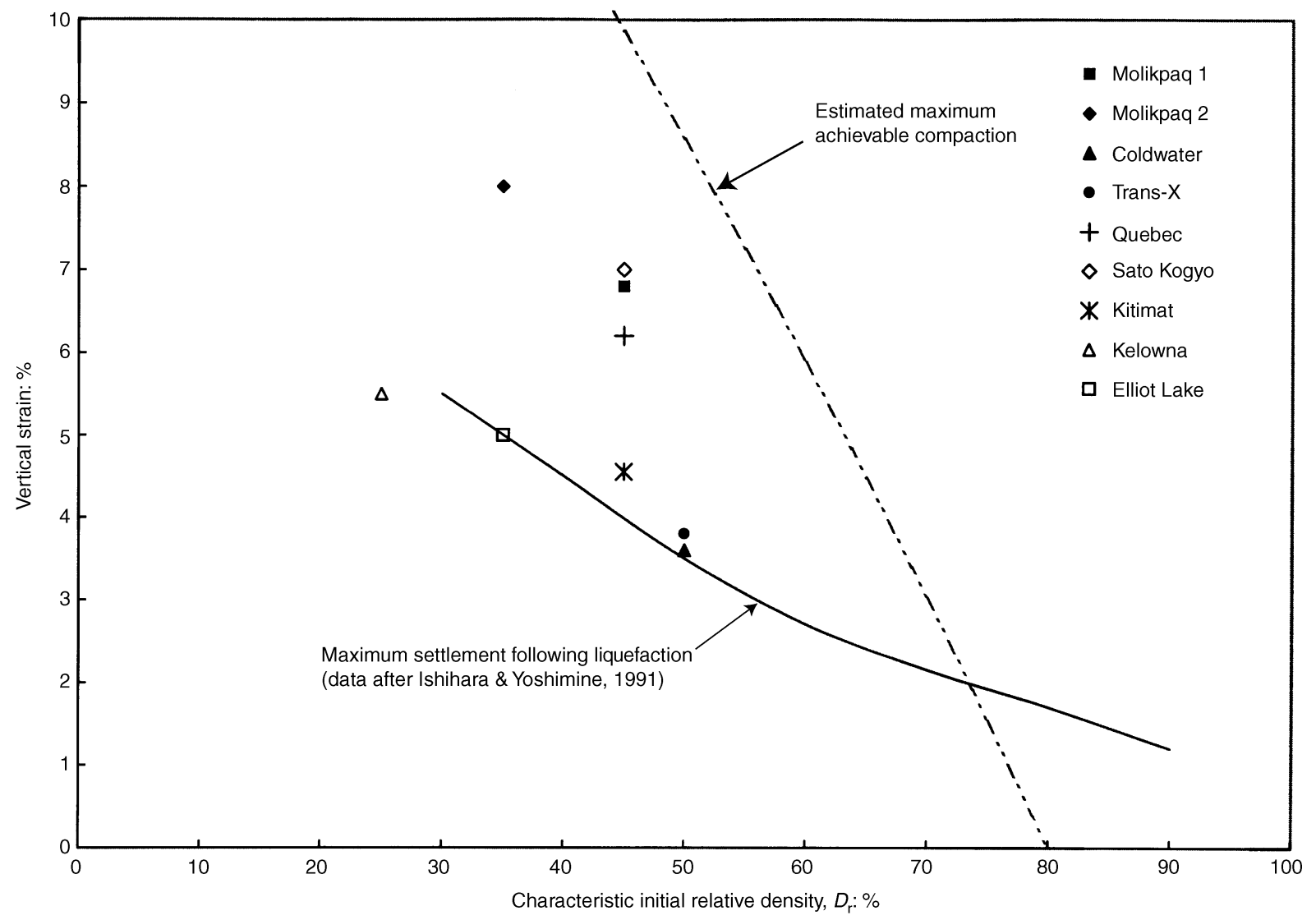

Fig. 4. Summary of settlements induced by explosive compaction 
passes are detonated once pore water pressures generated by the previous pass have dissipated sufficiently (typically 1 to 2 days).

Using multiple blast passes promotes increased settlement and more uniform densification. Because local soil loosening can occur immediately around a charge, subsequent passes of blasting from surrounding boreholes are designed to re-compact these initially loosened zones. At least two passes are usually required.

The explosive types have varied, and are selected based on safety, suitability for underground work, and handling convenience. Most recent projects have involved $1.5 \mathrm{~kg}$ cartridges (chubbs) of blasting emulsion. Detonators are invariably the non-electric (nonel) system for safety. It is also important to use delays to limit peak ground accelerations, to optimize the frequency content of the vibration, and to gain an adequate number of distinct cycles. The first goal is achieved by avoiding decks in adjacent boreholes detonating simultaneously: typically delays of tens of milliseconds will be used between holes. The second goal is achieved by using long-period delays between the various decks in a hole - often $500 \mathrm{~ms}$ (which is usually close to the site response frequency). The third goal is achieved by shooting multiple decks in a blast: at least three, and as many as seven (the practical limit with convenient casing sizes). Stemming, typically $1-2 \mathrm{~m}$ of pea gravel, is used between decks to avoid sympathetic detonation.

\section{TYPICAL DENSIFICATION RESULTS ACHIEVED}

The authors have been involved in a total of six production EC projects and several additional field trials where EC has been carried out to examine the effectiveness of the densification process (judged from settlements or change in penetration resistance). These case histories are summarized in Table 1, with Fig. 4 showing achieved settlements plotted in terms of initial relative density. The effectiveness of EC is readily apparent from the settlements, with average volume changes over the densification zone in the range $4-10 \%$. As expected, the settlement depends on the initial relative density of the deposit, soil gradation, and the blast design used.

Sand settlement could be viewed as plastic compression following a rather extreme initial excess pore pressure distribution, equivalent to a very large load increment ratio. But sands become progressively stiffer as they approach their minimum void ratio (Jefferies \& Been, 2000). Large excess pore pressure ratios do not mean large strains with granular materials. As a first approximation, for vertical stress levels of less than about $1 \mathrm{MPa}$, it is difficult to compact sands to a relative density of more than about $D_{\mathrm{r}} \approx 0 \cdot 8$. The maximum vertical strain to be expected is then

$$
\varepsilon_{\mathrm{v}}=\frac{0 \cdot 8-D_{\mathrm{r}}}{\left(1+e_{\max }\right) /\left(e_{\max }-e_{\min }\right)-D_{\mathrm{r}}}
$$

where $D_{\mathrm{r}}$ is the initial in-place relative density. For typical sand properties, equation (6) can be approximated as

$$
\varepsilon_{\mathrm{v}}=\frac{0 \cdot 8-D_{\mathrm{r}}}{4-D_{\mathrm{r}}}
$$

Equation (7) is plotted in Fig. 4 and compared with the case histories. The trend in the data is captured, with the data suggesting that about two thirds of the maximum possible settlement is obtained in practice. Also shown are expected settlements following earthquake-induced liquefaction based on Ishihara \& Yoshimine (1991).

For initial relative densities in the range $30-50 \%$, volume changes in the range $4-10 \%$ were achieved, corresponding to final relative densities in the range $65-80 \%$. As these strains have been distributed over substantial depths, induced settlements can be large: slightly more than $3 \mathrm{~m}$ settlement is the largest achieved to date. These settlements need to be considered when volumes of fill are being calculated for final site grading. Significant volumes of water will also escape where free-draining soils exist at the soil surface, and this may necessitate the construction of soil berms to prevent offsite flooding.

The site specific factors $k$ used for initial sizing of charges with equation (5) are also shown in Table 1. Sites with high attenuation (e.g. Coldwater Creek with its large boulders) show lower values of $k$ than do sites with more uniform sands (e.g. Trans-X and Quebec), while the two sites with energy reflection back into the fill (the Molikpaq cases) have apparently high $k$ values. Interestingly, the two Molikpaq cases had markedly different explosive charge layouts and yet give comparable $k$ values; this gives some confidence in the adequacy of equation (5) as a first approximation.

\section{ASSESSMENT OF DENSIFICATION AND TIME EFFECTS}

Penetration resistance (measured with the standard penetration test, SPT, or the more reliable cone penetration test, CPT) is typically used to assess the success of ground improvement, but this can be misleading - at least initially. Penetration testing may indicate little effect of blasting, while the large settlements indicate that considerable density increase has indeed been achieved. Time effects complicate the assessment of the success of EC.

Time effects can be at least partially explained by consideration of ageing in sands. Skempton (1986) presented data suggesting that the SPT resistance $\left(N_{1}\right)_{60}$ in normally consolidated sands increased by about $60 \%$ over a period of $100-200$ years from the time of deposition although there was little increase in $D_{\mathrm{r}}$. Prior to blasting, the $\left(N_{1}\right)_{60}$ obtained would include the effects of ageing. Immediately after blasting, these

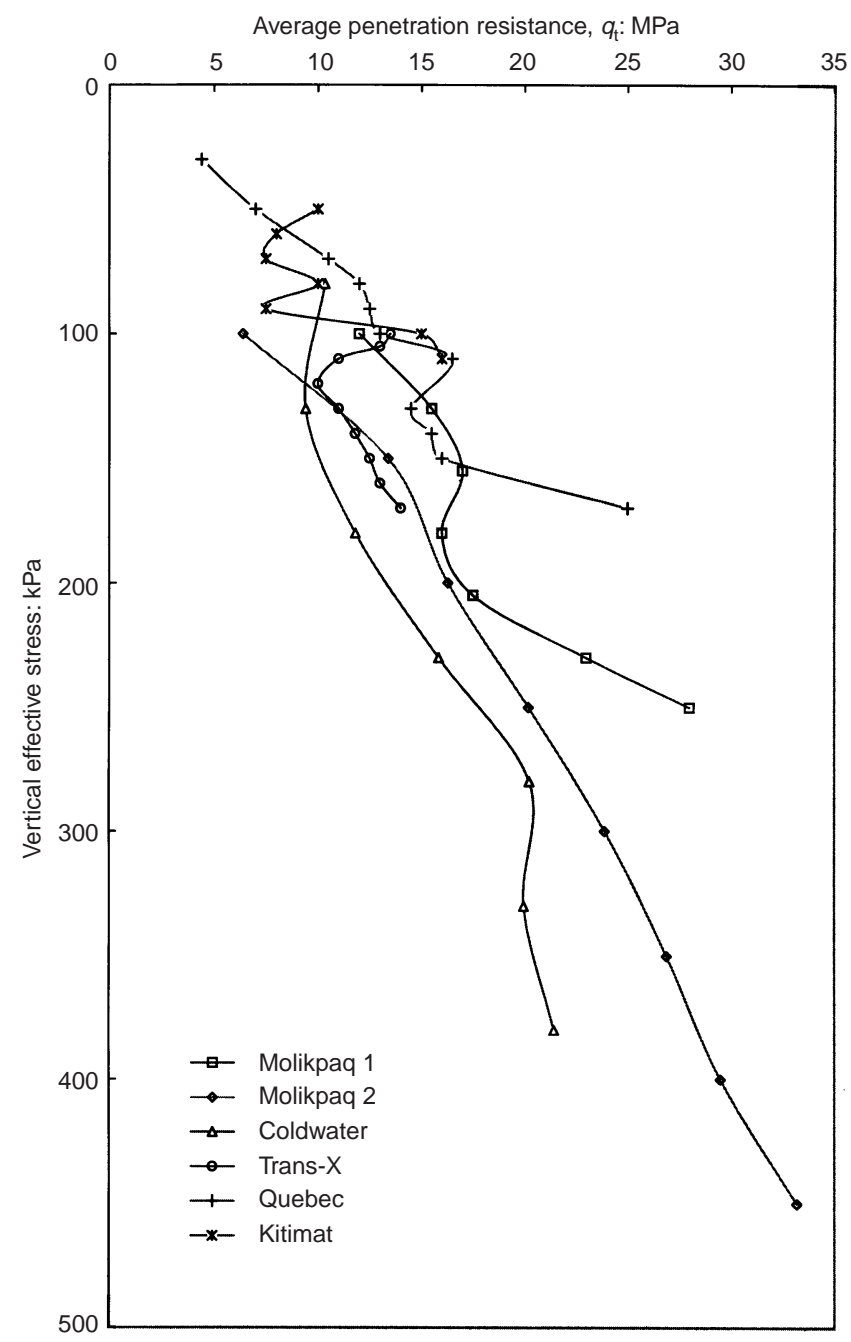

Fig. 5. Summary of average CPT resistance profiles after explosive compaction 
effects will have been destroyed, and SPTs measured after the blast could be lower than those existing before the blast, even though settlement indicates that the $D_{\mathrm{r}}$ has increased. The reduction in $\left(N_{1}\right)_{60}$ for several days to weeks following blasting is poorly understood, but is probably due either to the destruction of particle-to-particle bonds caused during sand diagenesis by secondary compression or chemical reactions at sand grain contacts, or to changes in soil structure and effective stress states in the soil mass caused by blasting. Given sufficient time following blasting, $\left(N_{1}\right)_{60}$ increases with time owing to the reestablishment of these ageing effects with little increase in $D_{\mathrm{r}}$. Time effects will also influence soil strength and stiffness, and this should be borne in mind during preparation of densification specifications. Time effects are also a factor in the assessment of other methods of densification (Mesri et al., 1990).

Achieved average cone penetration tests resistance $\left(q_{\mathrm{t}}\right)$ profiles are shown on Fig. 5 (the Coldwater Creek data have been transformed from the Becker test data at the site using a representative $q_{\mathrm{t}} / N$ ratio). Fig. 5 shows the average at each site without regard to the length of time for ageing: simply, this is the available data. These $q_{\mathrm{t}}$ profiles are thus not equivalent, and there are further differences in soil type so that equal $q_{\mathrm{t}}$ values do not imply the same density at the different sites. Nevertheless, the data illustrate the magnitude of average penetration resistance readily achieved by EC: in terms of stress-normalized CPT resistance the data indicate that on average it is straightforward to compact ground to better than $Q>70$, but equally it is difficult to achieve $Q>140$. For comparison, the critical state of sands corresponds to $Q \approx 35$ (see Been et al., 1987), so these achieved resistances indicate substantially dilatant behaviour of the compacted sands.

An important aspect of soils is their natural variability. Also, penetration resistance is affected by soil type (penetration resistance is a behaviour not a property). The effect of both of these aspects is illustrated in Fig. 6 for three of the case histories, showing the range of penetration resistance (at 95\% confidence - both low and high resistance spikes have been filtered) before and after EC. The Quebec case illustrates the situation with an alluvial sand, while the Coldwater Creek case shows the effects in a silty sand with cobbles and boulders (this site is in the Mount St Helens debris flow). The Molikpaq case shows what can be achieved with a hydraulically placed dredged sand. As can be seen, penetration resistances have been more than tripled by EC (judged by comparing minimum before with minimum after, average before with average after, etc.). The natural variability of penetration resistance (or density) appears to be unchanged or slightly increased by EC.

While settlement measurements should provide a more direct measure of compaction than penetration resistance, the use of surface settlement to evaluate EC is complicated by the difficulty of assessing initial $D_{\mathrm{r}}$ and by the need to ensure that the increase in density is consistent throughout the layer treated. Compaction uniformity with depth can be monitored by using
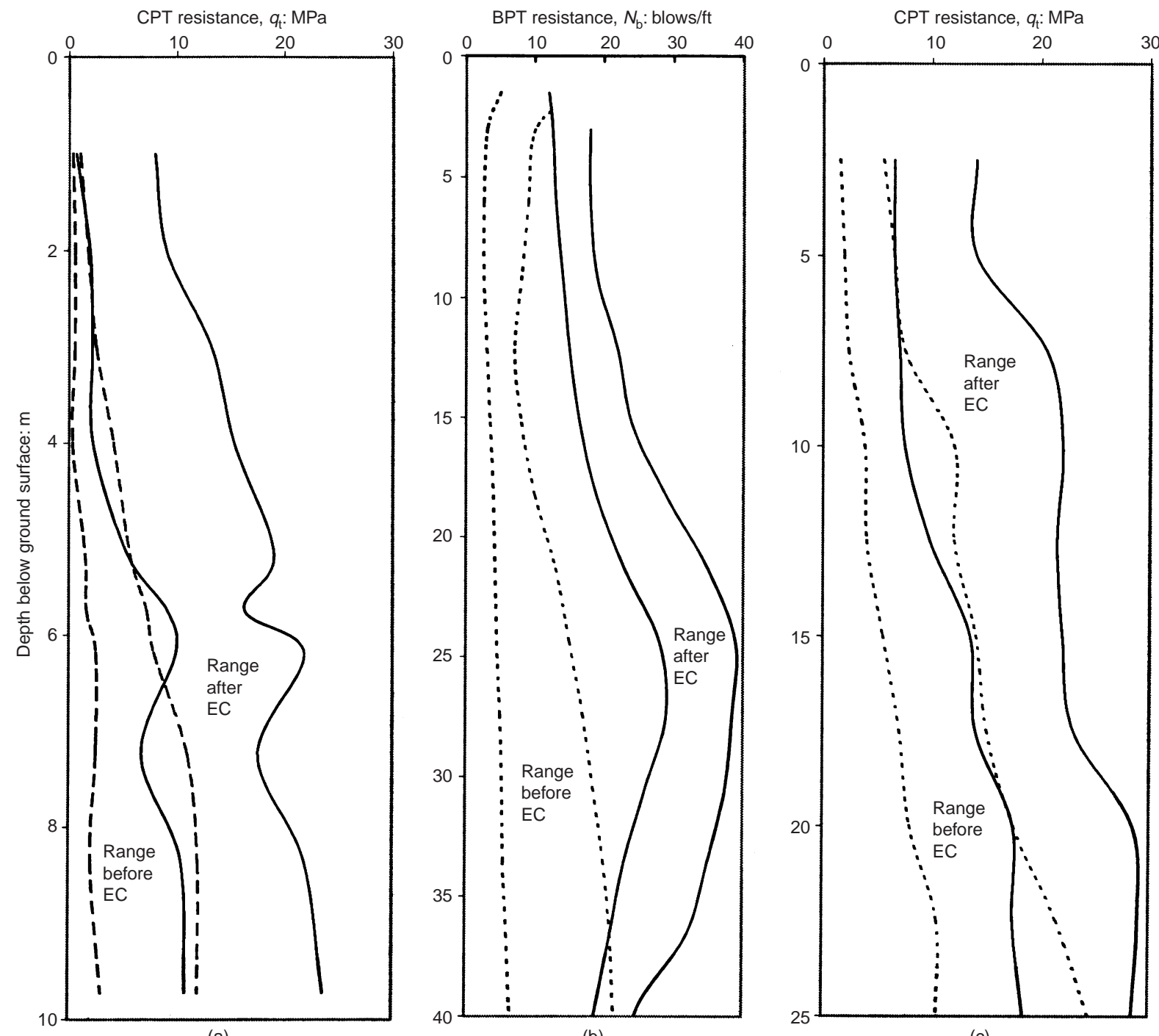

(b)

(c)

Fig. 6. Comparison of penetration resistance before and after EC showing range of data: (a) Quebec SM3 Dam (alluvial finecoarse sand): (b) Coldwater Creek (silty sand and gravel); (c) Molikpaq Amauligak (dredged medium-fine sand) 
deep settlement gauges placed at selected depths within the layer. Experience at reasonably homogeneous clean sand sites where the distribution of settlement with depth has been measured has shown that uniform settlement can be achieved (Fig. 7).

It seems likely that a combination of the use of settlement measurement and penetration testing will continue to be necessary to measure the performance of EC. Experience indicates that considerable increases in penetration resistances can be achieved in clean sands. These resistances are consistent with the increase in density from achieved settlements. In more silty soils, considerable settlements can still be achieved but penetration resistances will not be as great as at sand sites. All densification methods experience this effect, which is commonly misinterpreted as inadequate compaction.

\section{ENVIRONMENTAL ISSUES}

Below-ground explosive detonations result in large amounts of gas being released into the soil-water system, in the form of nitrogen oxide, carbon monoxide and carbon dioxide. Nitrogen oxide is inert in terms of environmental effects on groundwater. Release of carbon dioxide may lower the $\mathrm{pH}$ of the groundwater temporarily, while ammonia levels may also be temporarily elevated. But both nitrogen oxide and carbon monoxide are poisonous in air and venting is necessary if blasting is carried out within confined spaces.

In general, the chemical make-up of a particular explosive and its by-products should be reviewed for every project in order to assess its suitability for use at a particular site. Recently, the authors were involved at a trial EC project where extensive groundwater monitoring was carried out to assess the

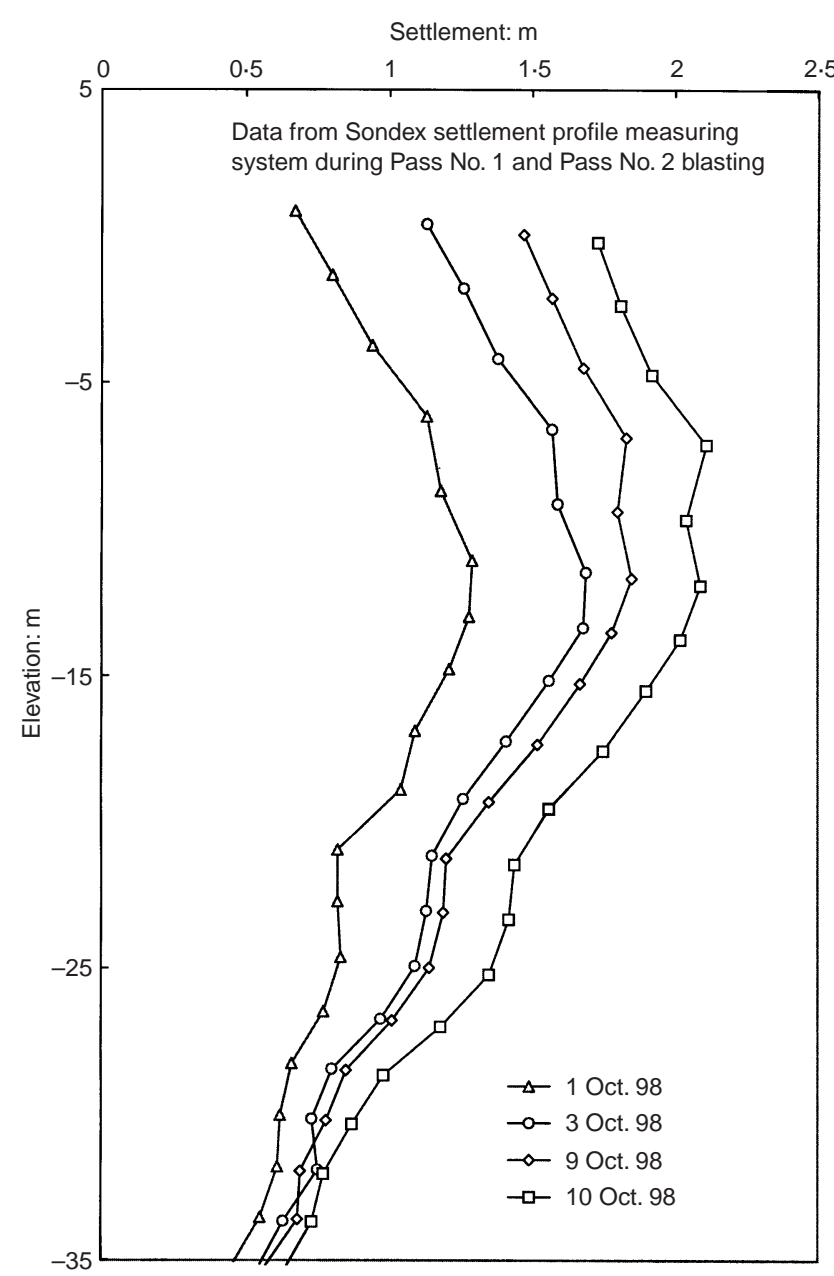

Fig. 7. Example of settlement profiles induced by explosive compaction impacts of blasting on groundwater. While short-term spikes in ammonia levels were noted in close proximity to the blast zone, measurable increases diminished a short distance from the blast.

Where blasting is carried out under bodies of water, the impact of the blast-induced percussive wave on resident fish populations needs to be assessed. Blast effects can be minimized through the installation of air bubble curtains around the blast zone or by using special sonic devices to drive fish away from an area.

\section{CONCLUSIONS}

Explosive compaction is effective and predictable. Explosive weighting follows from laws of similitude, although site attenuation factors may require further consideration. Current numerical simulators are adequate for blast design, although test blasts remain very desirable at any site before production blasting. Induced settlement (densification) depends strongly on the initial density and less strongly on the soil properties. Penetration resistances should not be the only measure of improvement unless time and soil type effects are taken into consideration.

\section{ACKNOWLEDGEMENTS}

The projects whose data are reported here were carried out for various companies including Gulf Canada Resources, Washington Dept of Transport (WASHDOT), Quebec Hydro, and Sakhalin Energy Investment. We are grateful for the support of these companies and the opportunity for such innovative work. We also acknowledge the support of our former colleagues at Agra Earth \& Environmental and Golder Associates. In particular, we should like to express our appreciation to Herb Hawson (Golder Associates) and Brian Rogers (formerly Gulf Canada, now Klohn Crippen) without whose support and encouragement much of this work would not have happened. Ron Elliot (Pacific Blasting) was the registered blaster in charge of explosive handling for these projects.

\section{NOTATION}

$D_{\mathrm{r}}$ relative density

e void ratio

$g$ gravitational acceleration

$h$ burial depth to centre of charge

$H N$ Hopkinson's number

$k$ site-specific attenuation factor

$\left(N_{1}\right)_{60} \quad$ SPT blow count normalized to $100 \mathrm{kPa}$ and $60 \%$ of maximum potential energy

$N_{\mathrm{b}}$ Becker penetration test resistance blow count

$Q$ stress-normalized CPT resistance, $\left(q_{\mathrm{t}}-\sigma_{\mathrm{v}}\right) / \bar{\sigma}_{\mathrm{v}}$

$q_{\mathrm{t}}$ cone penetration resistance corrected for tip unequal area effects

$r$ radial distance

$R$ radius of a circle of equal area to the rectangular/triangular region compacted by a blast hole

$t$ time

$V_{\mathrm{s}}$ soil shear wave velocity

$W$ mass of explosive charge $(\mathrm{kg})$

$z$ equivalent cube side dimension of explosive charge

$\varepsilon_{\mathrm{v}} \quad$ vertical strain

$\lambda$ slope of critical state line in $e-\ln p^{\prime}$ space

$\rho$ density of explosive charge

$\sigma_{v}, \bar{\sigma}_{\mathrm{V}}$ vertical stress and vertical effective stress respectively

$\varphi^{\prime} \quad$ friction angle

\section{REFERENCES}

Been, K., Jefferies, M. G., Crooks, J. H. A. \& Rothenburg, L. (1987). The cone penetration test in sands. Part 2: General inference of state. Géotechnique 37, No. 3, 285-299.

Chadwick, P., Cox, A. D. \& Hopkins, H. G. (1964). Mechanics of deep underground explosions. Proc. R. Soc. London Ser. A 256, No. 1070, 235-300.

Dobry, R., Ladd, R. S., Yokel, F. Y., Chung, R. M. and Powell, D. (1982). Prediction of pore pressure buildup and liquefaction of 
sands during earthquakes by the cyclic strain method, NBS Building Science Series 138. Washington, DC: National Bureau of Standards.

Higgins, C. J., Johnson, R. L. \& Triandafilidis, F. E. (1978). Simulation of earthquake-like ground motions with high explosives, Final report. Albuquerque, NM: University of New Mexico, Department of Civil Engineering.

Ishihara, K. \& Yoshimine (1991). Evaluation of settlements in sand deposits following liquefaction during earthquakes. Soils Found. 32, No. 1, 173-188.

Jefferies, M. G. and Been, K. (2000). Implications for critical state theory from isotropic compression of sand. Géotechnique 50, No. 4, 419-429.

Mesri, G., Fang, T. W. \& Benak, J. M. (1990). Post-densification penetration resistance of clean sands. J. Geotech. Engng Div. ASCE 116, No. 7, 1095-1115.

Rogers, B. T., Graham, C. A. \& Jefferies, M. G. (1990). Compaction of hydraulic fill sand in Molikpaq core. Proc. 43rd Can. Geotech. Conf., Canadian Geotechnical Society 2, 567-575.

Skempton, A. W. (1986). Standard penetration test procedures and the effects in sands of overburden pressure, relative density, particle size, ageing and overconsolidation. Géotechnique 36, No. 3, 425-447.

Stewart, H. R. and Hodge, W. E. (1988). Molikpaq core densification with explosives at Amauligak F-24. OTC 5684, Proc. 20 ${ }^{\text {th }}$ Annual Offshore Technology Conf, Houston.

Wu, G. (1995). A dynamic response analysis of saturated granular soils to blast loads using a single phase model. Research report submitted to Natural Sciences and Engineering Research Council (Canada), December 1995.

$\mathrm{Wu}, \mathrm{G}$. (1996). Volume change and residual pore water pressure of saturated granular soils to blast loads. Research report submitted to Natural Sciences and Engineering Research Council (Canada), December 1996. 